\title{
Cerebrospinal fluid data compilation and knowledge-based interpretation of bacterial, viral, parasitic, oncological, chronic inflammatory and demyelinating diseases. Diagnostic patterns not to be missed in neurology and psychiatry
}

Liquido cefalorraquidiano: compilação dos dados e interpretação avançada de doenças bacterianas, virais, parasitarias, oncológicas, inflamatórias cronicas e desmielinizantes. Padrões diagnósticos que não devem faltar em neurologia e psiquiatria Hansotto Reiber

\begin{abstract}
The analysis of intrathecal IgG, IgA and IgM synthesis in cerebrospinal fluid (CSF) and evaluation in combined quotient diagrams provides disease-related patterns. The compilation with complementary parameters (barrier function, i.e., CSF flow rate, cytology, lactate, antibodies) in a cumulative CSF data report allows a knowledge-based interpretation and provides analytical and medical plausibility for the quality assessment in CSF laboratories. The diagnostic relevance is described for neurological and psychiatric diseases, for which CSF analysis can't be replaced by other diagnostic methods without loss of information. Dominance of intrathecal IgM, IgA or three class immune responses give a systematic approach for Facial nerve palsy, Neurotrypanosomiasis, Opportunistic diseases, lymphoma, Neurotuberculosis, Adrenoleucodystrophy or tumor metastases. Particular applications consider the diagnostic power of the polyspecific antibody response (MRZ-antibodies) in multiple sclerosis, a CSF-related systematic view on differential diagnostic of psychiatric diseases and the dynamics of brain-derived compared to blood-derived molecules in CSF for localization of paracytes.
\end{abstract}

Keywords: cerebrospinal fluid; immunoglobulins; antibody; nervous system diseases; clinical record.

RESUMO

A análise da síntese intratecal de lgG, IgA e IgM no liquido cefalorraquidiano (LCR) e a avaliação destas em diagramas com quocientes sugere padrões de diversas doenças. Estes dados, juntamente com outros parâmetros como a função de barreira, o fluxo liquórico, a citologia, o lactato e a pesquisa de anticorpos, integrados em uma ficha de paciente, permite uma interpretação baseada em conhecimento e permite também uma aferição da qualidade em laboratórios de LCR. A relevância diagnóstica é descrita para doenças neurológicas e psiquiátricas pois a análise do LCR não pode ser substituída por outros metódos diagnósticos sem perda de informação para o diagnóstico do paciente. 0 aumento da síntese intratecal de IgM, IgA ou das 3 classes de imunoglobulinas sugerem um diagnóstico sistemático de paralisia facial periférica, neurotripanosomiase, doenças oportunísticas, linfoma, neurotuberculose, adrenoleucodistrofia ou metástases de tumores cerebrais. A resposta poliespecífica de anticorpos contra sarampo, rubéola e varicela zoster (MRZ reação) é sugestiva de esclerose múltipla. Uma visão sistemática considera o diagnóstico diferencial de doenças psiquiátricas e doenças chrônicas. A dinâmica de moléculas derivadas do cérebro comparadas com aqueles derivadas do sangue é importante para a localização de parasitos em doenças parasitárias do sistema nervoso.

Palavras-chave: liquido cefalorraquidiano; imunoglobulinas; anticorpos; doenças do sistema nervoso; doenças neurológicas; ficha clínica.

Georg August-University, Former Neurochemistry Laboratory, Goettingen, Germany.

Correspondence: Hansotto Reiber; CSF and Complexity Studies; Rua Piaui, 163; 01241-001 Sao Paulo SP Brasil; E-mail: ho@horeiber.de

Conflict of interest: There in no conflict of interest to declare.

Received 25 November 2015; Received in final form 30 December 2015; Accepted 07 January 2016. 
Cerebrospinal fluid (CSF) analysis for differential diagnosis of neurological diseases is still, 120 years after start of diagnostic CSF puncture ${ }^{1}$, not to be replaced without serious loss of basic, unique information. CSF analysis ${ }^{2,3}$ can provide information about many acute and chronic inflammatory, dementive, oncological or haemorrhagic pathological processes in the brain which can be provided neither by established electrophysiology nor by actual brain imaging techniques. This emphasizes the demand to perform CSF analysis with the highest possible quality ${ }^{3,4}$. There is much knowledge collected about particular analytical parameters relevant for confirmation of the suggested diagnosis of a disease $^{2}$. But the request for the particular analysis of a single specific parameter needs the preceeding exploration of the symptom-related diagnostic options. This is the rational behind a basic CSF analysis program which can point to, or exclude diagnostic suggestions. Such a CSF program ${ }^{5}$ is based on the compilation of the complete spectrum of all CSF data from the individual patient in a cumulating CSF data report $^{3,6}$. The recognition of disease-related or disease-specific data patterns have been the rational for the development of knowledge-based interpretation software ${ }^{6}$. These concepts are meanwhile applied to many other fields of clinical chemistry, eventually associated with on-line data acquisition on nephelometer automats ${ }^{6,7,89}$. A multilingual approach of A. Wormek $^{6}$ (http://www.wormek.org/csf.jsp) is open for development of an individualized Portuguese version.

Regarding the accumulated knowledge with this concept, it is hard to understand why many CSF laboratories in particular in wealthy countries, like the North Americas, offer very restricted CSF programs, eventually without an essential, concomittant serum analysis. The reluctance of many neurologists, which perform the lumbar CSF puncture only in rare cases, may be due to a combination of different deficits due to their educational tradition, economical conditions and health politics of their country or most unsatisfying due to a bad performance in their CSF laboratory.

CSF analysis for neurological and psychiatric diseases with a complete immunoglobulin class response (IgG, IgA, IgM) can provide not only a disease-related, typical pattern, it also can help to propose the best specific parameter to be analysed subsequently satisfying the diagnostic request. In particular where a classical culture technique for detection of the causative microorganism would need much to long (days to weeks) or a faster PCR analysis would be not sensitive enough, the detection of such an immunoglobulin pattern, analysed in a few hours, could give evidence for a fast decision for further investigations or immediate treatment.

Missing IgA and IgM analysis often means to miss an unexpected diagnosis or the clue for a differential diagnosis. As an example, CSF analysis is the only method to discriminate the possible causes of a treatable facial nerve palsy: The treatment of a patient for a viral cause in case of a bacterial inflammation is a serious risk to harm this patient's health.
The same is true for diagnostics in psychiatry: The symptomatic treatment of a psychiatric patient suffering from a bipolar spectrum disorder could be found wrong, if the CSF analysis shows an inflammatory cause.

In this review I want to show the relevance of a CSF analysis in the tradition of the cumulative CSF data report ${ }^{3,5,6}$. This compilation of all data of the individual patient considers the immunoglobulin response in the context of cytology, blood CSF barrier function, lactate and specific antibodies.

The following examples may be representative for the power of this approach:

- cause of a facial nerve palsy (IgM in differential diagnosis);

- neurotrypanosomiasis - (IgM for detection of brain involvement);

- neuroborreliosis - (Dominance of IgM in typical three class pattern);

- Non-Hodgkin lymphoma in the brain (exclusive IgM, and opportunistic tumor);

- brain abscess (IgA);

- neurotuberculosis, (IgA, lactate and QAlb);

- Xlinked adrenoleucodystrophy (exclusively dimeric IgA);

- neurosyphylis (no IgA synthesis, IgM discriminates different pathologies);

- opportunistic infection in HIV encephalitis (three class Ig response);

- monosymptomatic multiple sclerosis/ADEM (MRZ antibodies);

- psychiatric diseases with brain-organic cause of symptoms (oligoclonal IgG, marker proteins, barrier function, neopterin);

- localization of paracytes in subarachnoid space.

I am aware that in many parasitic and tropical diseases ${ }^{10,11,12,13}$ after neuroimmaging the essential cytologic investigation in $\mathrm{CSF}^{11,12,14}$ and also blood-based analytical procedures have priority. But the analysis of the basic immunoglobulin pattern like in the African trypanosomiasis ${ }^{10}$ or Angiostrongylus infection ${ }^{13,15}$ may contribute to a faster and safer diagnosis of the brain involvement. A new perspective for localization of the paracytes comes from the different dynamics of blood- and brain-derived molecules in $\mathrm{CSF}^{16,17}$.

A complementary review in this journal ${ }^{4}$ provides the physiological and biophysical knowledge base of CSF data interpretation together with reference values and comments for the analytical aspects of the corresponding analytes ${ }^{18}$.

The conceptual approach to CSF analysis ${ }^{5,19}$ is not only a responsible act for the patients sake, it is also of imminent economical relevance. A complete CSF analysis saves money for the society by avoiding late or wrong treatments with an eventually dramatic increase of hospital costs.

Comments of several colleagues regarding their countries health politics encouraged me to write this review with the hope that it helps to improve the situation for their patients. But if neurologists don't ask for and clinical chemists don't provide the options, the public health system will not provide the financiation. 


\section{COMPILATION OF CSF DATA IN THE CSF REPORT FOR THE INDIVIDUAL PATIENT}

An example of a cumulative CSF data report ${ }^{5,6,19}$, including the graphical representation of the immunoglobulin response pattern is shown in Figure 1 from a patient with neurotuberculosis. The compilation of CSF data in a cumulative report was invented in the 1970ies in the Neurochemistry laboratory in Goettingen by Helmut Bauer and Sigrid Poser, including the qualitative "Normo-Mastix curve", later replaced by the quantitative Reibergrams $s^{3,5}$, to facilitate the pattern recognition "at one glance". Up today the cell count, total protein and lactate are the base for emergency analysis. The complete basic CSF program with visual inspection of CSF, Hgb, differential cell count and the fast analysis of albumin, IgG, IgA, IgM can be finished a few hours after CSF and blood extraction. An essential part of this CSF report is the implementation of the anamnestic informations from the neurologist like age of the patient, the suggested diagnosis or differential diagnostic questions. An extended analysis with more specific parameters may be based on this initial information.

The central part of any CSF analysis is the numerical or graphical evaluation of the intrathecal immune reaction and the detection of a barrier dysfunction. This has an old tradition ${ }^{1}$ with many different historical solutions.

Early quantitative evaluations in quotient diagrams ${ }^{20}$, were steadily improved and extended ${ }^{21,22}$ to the todays Reibergrams $s^{3,5}$ or Reibergramas ${ }^{23}$ in Spanish speaking countries. Their theoretically founded, nonlinear discrimination between blood-derived immunoglobulins (Ig) and fractions from intrathecal Ig-synthesis (hyperbolic Qlim, bold line in Figures 1-6) replaced or should have replaced the linear IgG- or IgM-Index with their false interpretations ${ }^{5,24}$. As an important mile stone, the theoretical foundation of the hyperbolic reference ranges in quotient diagrams by the molecular diffusion/CSF flow mode ${ }^{22}$ led to a completely new view on the blood CSF barrier function. The common use of terms like "leakage", "barrier impairment" or "barrier breakdown" to describe an increased QAlb, is misleading and not founded by any hard facts. The only reason for an increased QAlb, i.e., a blood CSF barrier dysfunction, is the decrease of the CSF flow rate $^{22}$ (s. complementary review ${ }^{4}$ ).

The quotient diagrams (Reibergrams) present both information about immune response pattern and barrier function recognizable at one glance and are central part of the data evaluation in the cumulative CSF report.

The interpretations in the CSF report ${ }^{5,6,19}$ from the routine laboratory data analysis includes three subsequent interpretation steps:

1) The reference range-related evaluation of analytical values for the individual parameter which allows to decide between normal, pathological and eventually borderline values.

2) Evaluation of the combined data set which gives medical and analytical information in a standard set of choices based on physiological, biochemical, biophysical and clinical knowledge from neurological diseases (s. complementary review ${ }^{4}$ ).

3) Case-related variable comments of diagnostic and analytical relevance (examples with the corresponding parameters, s. complementary review ${ }^{4}$ ). These may help to see the results critical with respect to analytical problems or sample conditions observed, but also can point to differential diagnostic alternatives or can propose further analysis.

A basic set of standard interpretations ${ }^{6}$ may contain:

- normal CSF-data;

- normal protein data in CSF;

- cell count increased;

- lactate increased;

- intrathecal antibody synthesis;

- inflammatory process;

- blood CSF barrier dysfunction, eventually extended by pathological dementia-marker and intrathecal CEA synthesis.

Other examples of the free comments ${ }^{6,19}$ are associated with the single paragraphs in the following text.

An example of the interpretation steps in Figure 1 for a neurotuberculosis (TB) looks like:

1) Cell count increased, Age-related QAlb pathological, QIgA $>$ QIgG und $\operatorname{IgA}_{\mathrm{IF}}>0 \%$, lactate increased $>3.4 \mathrm{mmol} / \mathrm{l}$.

2) Blood CSF barrier dysfunction, Inflammatory process, Intrathecal IgA synthesis,.

3) The combination of an intrathecal IgA synthesis, pathologically increased lactate $(>3.4 \mathrm{mmol} / \mathrm{l})$, a severe blood CSF barrier dysfunction and intermediate increase of the cell count is a typical result found with a very high plausibility for neurotuberculosis. The correspondingly specific investigations for TB are adviced.

\section{Knowledge-based data interpretation}

The software-supported, knowledge-based data interpretation $^{25}$, was created to support the informed clinical chemist or neurologist, but not to replace the expert, what the initial "expert systems" intended to do. The quality of a knowledge-based data interpretation depends on the number of analytical and diagnostic parameters involved. Any additional information may change the interpretation. What seems to be a normal report with only IgG analysed, may become an inflammation or tumor if intrathecal IgM is found, or the normal "complete" CSF report may lead to the intrathecal VZV antibody detection if the clinician communicates that the patient suffers from a facial nerve palsy (Figure 2).

So, a knowledge based data interpretation on a large data base helps to avoid wrong interpretations and points to further analysis in the daily laboratory routine but remains to be controlled by the experienced neurologist or psychiatrist to find the final diagnosis.

This diagnostic approach of a software-supported, on-line data acquisition from nephelometric protein assays, together with knowledge based interpretations and comments (Figure 1$)^{4}$ became the model for the different professional 


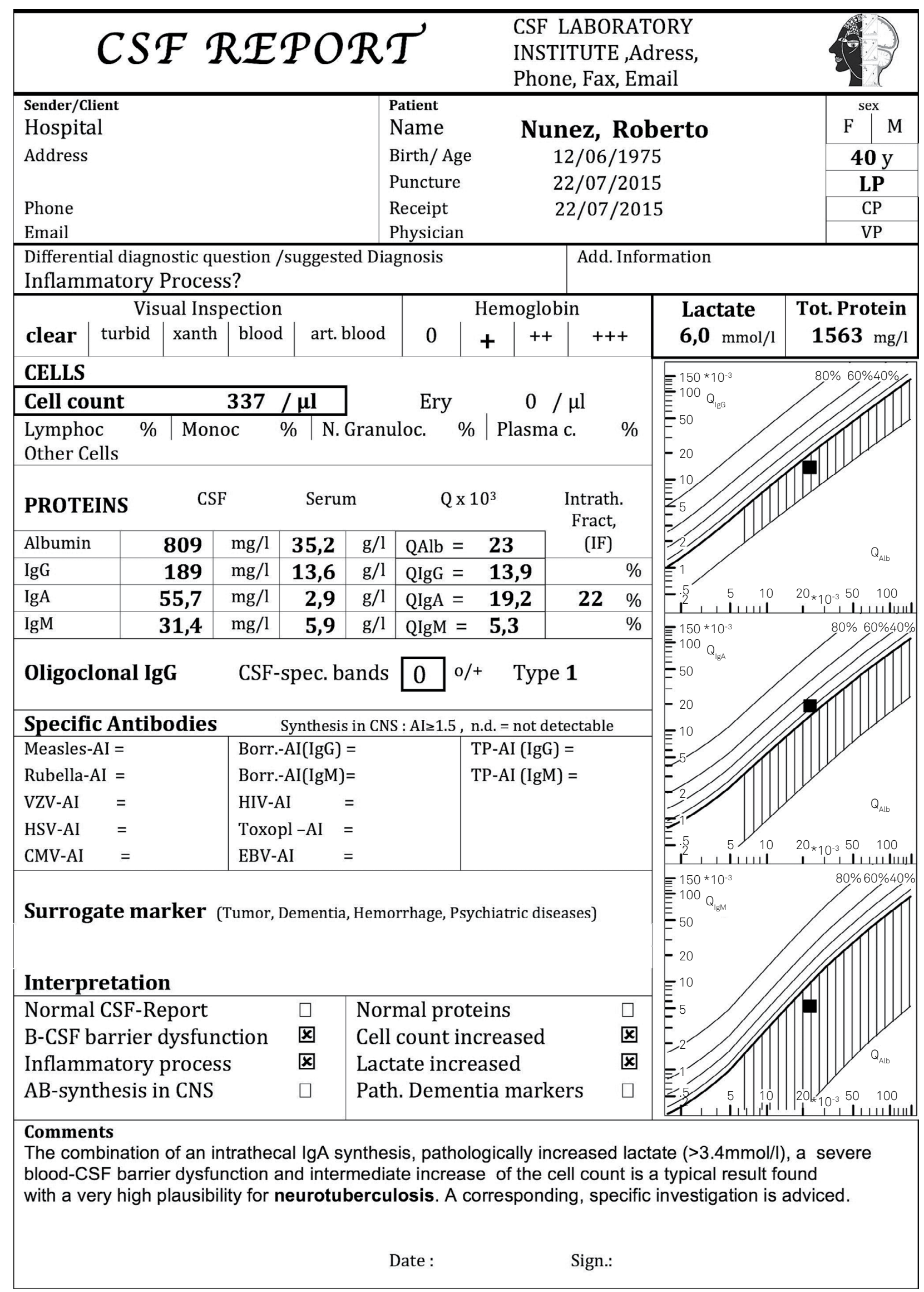

Figure 1. Cumulative CSF Report of all data from a patient with Neurotuberculosis. The concept of a knowledge based data interpretation is described in the text $3,4,5$. The set of fixed intepretations and examples of possible free comments are given in the text or reported earlier ${ }^{6}$. This English report is drafted by Reiber H, 2016. 


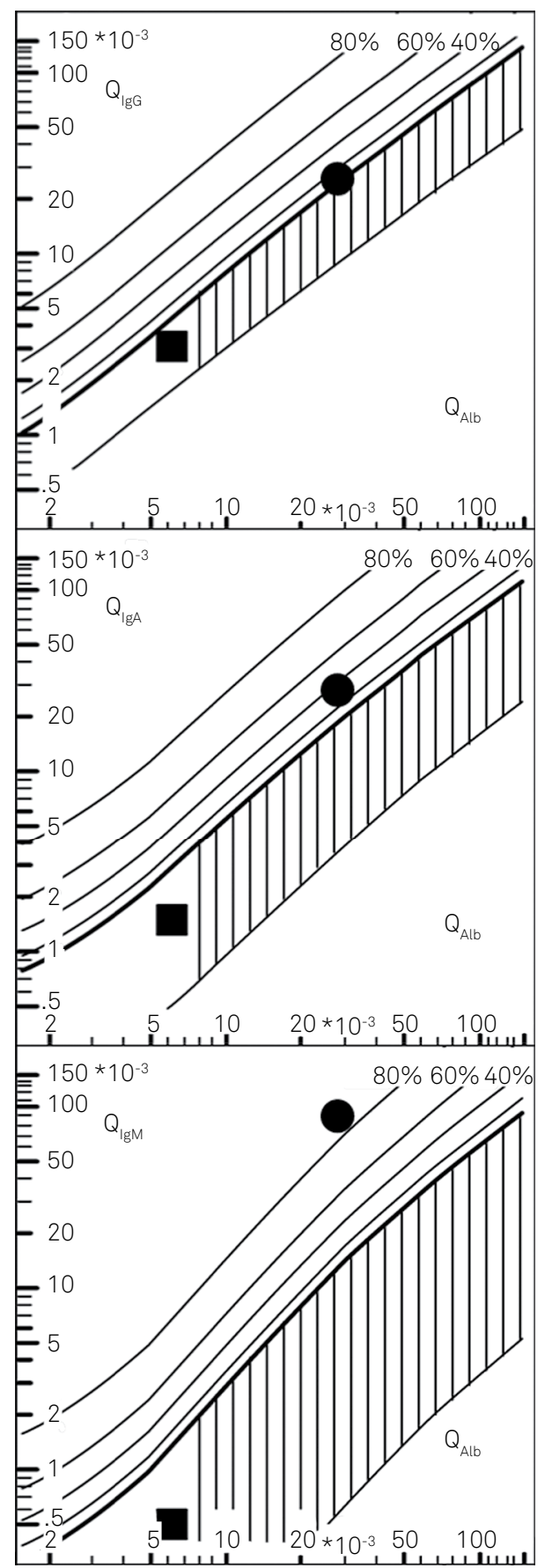

Figure 2. Differential diagnosis of facial nerve palsies. The normal pattern was associated with a VZV-AI (IgG) = 4,6 and the three class immune response pattern (with oligoclonal IgG) was associated with a Borrelia-AI(IgG) $=11,2$. The diagram is developed with the free CSF program (www.albaum.it).

laboratory software solutions $s^{5,6,7,89,23}$. The basic knowledge base is reported in the complementary review in this issue ${ }^{4}$

\section{CSF - DATA PATTERNS IN SELECTED NEUROLOGICAL DISEASES}

The selection of the following diseases is based on the particular relevance of the IgM- and IgA- synthesis in the frame of the complete immune response pattern. But this does not mean that diagnosis of the many other diseases would not benefit from this general approach. Depending on the diagnostic question of the neurologist or psychiatrist patterns can either lead to a subsequent more specific analysis or by exclusion of the suggested diagnosis pointing to an unexpected disease. A more complete table with the disease-related relevance of CSF parameters is given in the textbook ${ }^{19}$.

IgG: The intrathecal IgG synthesis is the most frequent immune response detectable in $50 \%$ of the inflammations in the daily routine CSF analysis. This means that these cases are much more dependent on the information from accompaning analysis. Intrathecal IgA- or IgM-analysis with only half the frequencies ${ }^{9}$ have a much higher discriminative power.

IgM: The interpretation of an intrathecal IgM analysis is different from blood IgM: It is not a sign of the acute phase of a disease as the isotype switch occurs not in brain ${ }^{26}$.

IgA: $90 \%$ of the blood-derived IgA in CSF passes the barriers as the monomeric molecule. The intrathecally synthesized IgA is primarily the dimer ${ }^{27}$, like in mucosal secretions ${ }^{28}$.

IgG + IgA + IgM: A basic help for the differential diagnosis comes from the classification of a one, two, or three class immune response with determination of a predominant intrathecal immunoglobulin class response $\left(\right.$ review $\left.^{4}\right)$.

These specific analytical patterns have no particular pathophysiological meaning. The influences are very complex, like time course and localization of the disease process. As described for Multiple sclerosis (MS), immigration of specific $B$ cells into the brain is arbitrary and may vary locally in the individual patient ${ }^{26}\left(\right.$ review $\left.^{4}\right)$.

\section{Dominance of intrathecal IgM in CSF pattern}

\section{Facial nerve palsy}

With the communicated observation of a facial nerve palsy by the physician the immunoglobulin patterns in Figure 2 guide to the subsequent analysis:

- In case of the pattern with a predominant intrathecal IgM synthesis $\left(\operatorname{IgM}_{\mathrm{IF}}>\operatorname{IgA}_{\mathrm{IF}} \mathrm{IgG}_{\mathrm{IF}}\right)^{4}$ the subsequent analysis for a borrelia antibody synthesis leads to an antibiotic treatment.

- A normal Ig pattern, typical for the viral cause, led to detection of the increased Varicella Zoster Antibody Index (VZV-AI) with an antiherpetic treatment.

- An increased VZV-AI was accompanied by detectable oligoclonal $\operatorname{IgG}(\mathrm{OCB})$ only in about $50 \%$ of the cases. This is typical for an acute disease compared to a chronic disease like MS with a very high frequency of OCB (98\%).

- In case of a borrelia caused facial nerve palsy the immunoglobulin pattern matches well the pattern found in a neuroborreliosis ${ }^{29}$.

There is no other method available for the differential diagnosis of a facial nerve palsy which could replace CSF analysis. 


\section{Neuroborreliosis}

The three class immune response with a predominant IgM, weaker IgA and an occationally only by OCB detectable IgG synthesis (Figure 2) is very characteristic for this disease $e^{29}$, in particular if the lactate value is normal. In areas with a high incidence of borrelia infections the probability is very high, that a seropositve patient has another neurological disease (e.g. MS ${ }^{26,29}$ ). This makes such a pattern very relevant to avoid a false positive interpretation with wrong treatment. This frequent bias may be one of the reasons for interpretations like the so-called post lyme syndrome, eventually the consequence of another not diagnosed disease ${ }^{29}$.

\section{Neurotrypanosomiasis}

The African trypanosomiasis (trypanosoma ghanense or rhodense) is an example where CSF analysis with predominant intrathecal IgM synthesis in $95 \%$ of the cases ${ }^{10}$ (Figure 3) can give the safest detection of the involvement of the brain. The international definition (WHO) of a hemolymphatic first stage (CSF cell count $<5 / \mu \mathrm{l}$, no trypanosomes in CSF), an meningoencephalitic early $2^{\text {nd }}$ stage (cell count $6-20 / \mu$ in the absence of trypanosomes in CSF) and a late $2^{\text {nd }}$ stage (cell count $>20 / \mu \mathrm{l}$ or trypanosomes in CSF) have been shown to be unreliable ${ }^{10}$. Figure 3 represents a first stage patient with intrathecal IgM and also an early $2^{\text {nd }}$ stage patient without any intrathecal humoral immune response. Cases with absence of the brain involvement in spite of a (single) paracyte in CSF can be found as well. The intrathecal IgM synthesis, eventually accompanied by a weaker IgG and/or IgA synthesis (Figure 3), is crucial for the diagnosis of a neurotrypanosomiasis. These cases document that without an immunglobulin pattern analysis many false negative and false positive interpretations occur ${ }^{10}$. This is crucial for the patient as the treatments of a systemic disease is different from the effective treatment in case of a brain involvement ${ }^{30}$. Serum analysis may provide also an essential diagnostic information with this extremely high systemic IgM synthesis (Table), characteristic for paracytes with a fast, steadily changing surface protein pattern.

The presence of a single paracyte in the CSF is not sufficient to state unambiguously the involvement of the brain.

This disease is an example for the relevance of CSF analysis to exclude/detect at the earliest possible time safely an involvement of the brain, with relevant consequences for the best treatment of the patient.

For Chagas disease, the Latinamerican trypanosomiasis ${ }^{31}$, caused by trypanosoma cruzi, the detailled immunoglobulin response pattern is not available. But reports ${ }^{13}$ which state normal CSF values or only slight increase of proteins may represent the different pathomechanism as an expression of the parasitism described ${ }^{31}$.

\section{Non-Hodgkin lymphoma}

An isolated intrathecal IgM synthesis without any other neuroimmunological responses in CSF can be observed from

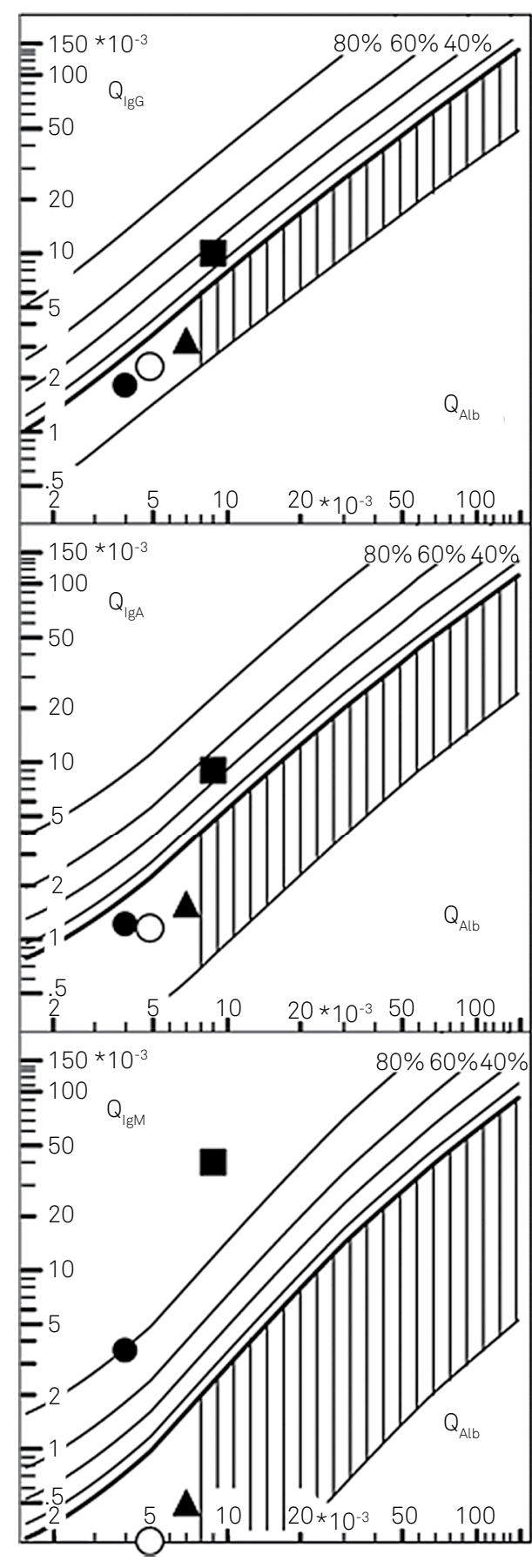

Figure 3. Cases of trypanosomiasis without and with involvement of the brain ${ }^{10}$. The WHO definition of a $1^{\text {st }}$ stage (open circles), an early $2^{\text {nd }}$ stage(triangles) and a late $2^{\text {nd }}$ stage (squares) are misleading as seen by the intrathecal IgM synthesis in a $1^{\text {st }}$ stage patient (filled circles) and the absence of an intrathecal humoral immune response in an early $2^{\text {nd }}$ stage patient (triangles). The late $2^{\text {nd }}$ stage (square) with a two to three class immune response with predominant IgM synthesis, increased cell count $(>20 / \mu \mathrm{l})$ and a lactate value $<3,4 \mathrm{mmol} / \mathrm{l}$ represents the best characterization of a neurotrypanosomiasis ${ }^{10}$.

a Non-Hodgkin lymphoma in the brain (Figure 4). It is important not to misinterprete such a result as an inflammation, e.g., by the sensitive exclusion of an intrathecal IgG (OCB) and IgA synthesis together with a corresponding cytology. 
Table. Relevance of CSF/serum quotients (Q). Examples from systemic African trypanosomiasis, first stage (without involvement of the brain). The normal serum and CSF/serum quotients values are from a European population ${ }^{3}$. The very low albumin concentration values and extremely high IgM concentration values in serum and subsequently in CSF of the patients with a systemic trypanosomiasis ${ }^{10}$ have nevertheless CSF/serum quotient values like a normal population. This example shows the relevance of quotients, $Q$, for a reliable comparison of CSF data.

\begin{tabular}{|c|c|c|c|c|}
\hline & \multicolumn{2}{|c|}{ Normal } & \multicolumn{2}{|c|}{ Trypanosomiasis $1^{\text {st }}$ stage } \\
\hline & Serum & $\mathrm{Q}$ & Serum & Q \\
\hline & Range (g/l) & $\begin{array}{l}\text { Mean } \\
\times 10^{3}\end{array}$ & Range (g/l) & $\begin{array}{l}\text { Median } \\
\times 10^{3}\end{array}$ \\
\hline Albumin & $35,0-55,0$ & 4,5 & $23,0-34,0$ & 3,8 \\
\hline $\lg G$ & ago/18,0 & 2,0 & $24,0-35,0$ & 1,8 \\
\hline $\lg A$ & $0,9-4,5$ & 1,1 & $1,5-3,4$ & 0,9 \\
\hline $\lg M$ & $0,6-2,5$ & 0,25 & set/18,0 & 0,2 \\
\hline
\end{tabular}

Only in the case of an opportunistic disease like in HIV encephalopathy (below) additional neuroimmunological signs have to be considered.

A possible comment in the CSF report could be:

- Isolated intrathecal IgM synthesis without other inflammatory signs (normal cell count, no oligoclonal $\operatorname{IgG}$ ) may indicate a Non-Hodgkin lymphoma.

General conclusions: A predominant intrathecal IgM synthesis can be observed in bacterial and parasitic as well as in viral diseases, like the mumps meningoencephalitis (not shown), but also in cases of an eventually opportunistic tumor. So, the interpretation as a typical disease-related pattern depends on the analytical context of complementary CSF parameters together with the communicated differential diagnostic question.

\section{Dominant intrathecal IgA in CSF patterns}

\section{Neurotuberculosis}

A predominant intrathecal IgA synthesis with a (severe) barrier dysfunction and significantly increased lactate in CSF represents a pattern which has almost no alternative interpretation to a neurotuberculosis (Figure 1 and comment example above). In some cases the IgA synthesis may be recognized initially only by the relation QIgA > QIgG in spite of a QIgA value borderline to the reference range in the quotient diagram. Occationally the intrathecal IgA synthesis is accompanied by oligoclonal IgG. An intrathecal IgM synthesis may be observed only in later course of the disease after a delayed start of treatment. Albumin quotients with up to $\mathrm{QAlb}=400 \times 10^{-3}$ indicate the seriously reduced CSF turnover rate. The PCR analysis is the method of choise to confirm the suggested disease $\mathrm{e}^{3,5}$.

In areas with a low incidence of tuberculosis the diagnosis of the neurotuberculosis may be suggested very late with a fatal consequence for the patient where the basic CSF

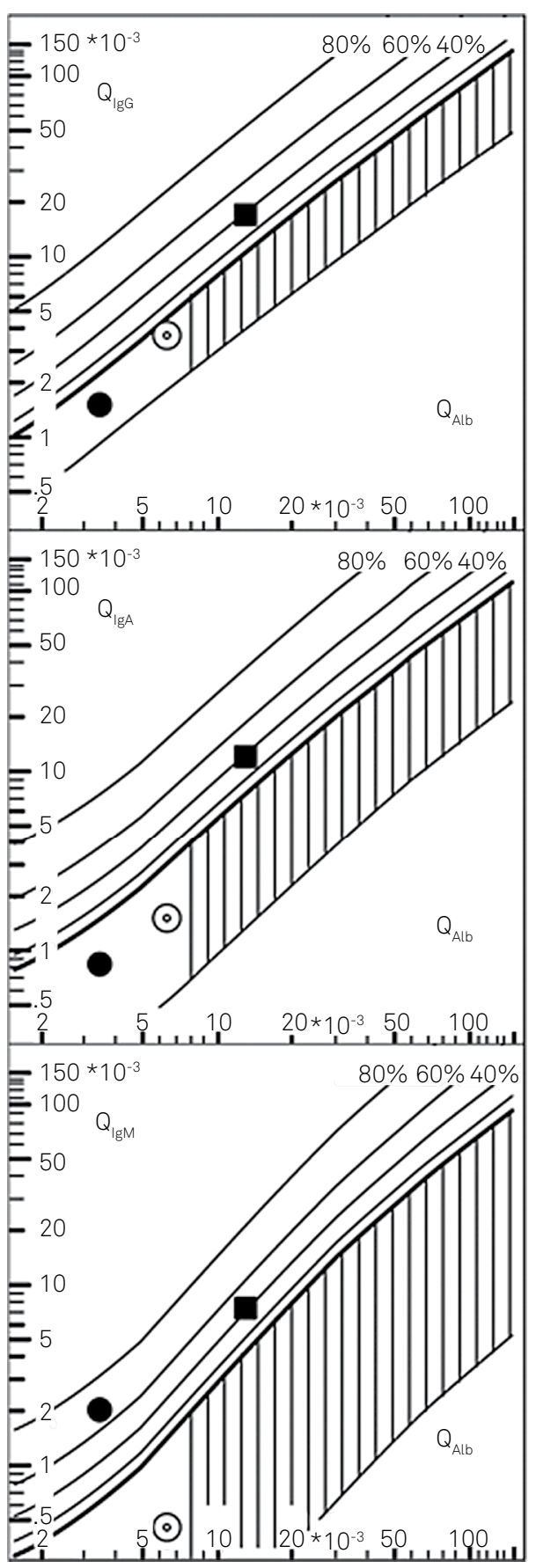

Figure 4. CSF of HIV positive patients with a HIV encephalopathy (open circles with center point) an opportunistic toxoplasmosis (squares) and an opportunistic Non-Hodgkin lymphoma (filled circles) ${ }^{19}$.

analysis could have given a clear hint to this diagnosis already at the first diagnostic CSF puncture. The classical confirmative culture needs to much time for an orienting differential diagnosis.

\section{Brain abscess - course of CSF data in a bacterial meningitis}

The repetition of lumbar puncture is rare, restricted to complicated cases. Earlier reports ${ }^{5,19}$ show the normal course 
of the immunoglobulin data after an immediate treatment of a bacterial meningitis without any humoral immune response. But complications seen after start of the treatment ${ }^{19}$, patients with multiple cortical abscesses after purulent meningitis ${ }^{5}$ or patients with risks like congenital heart defects ${ }^{5}$ show a most alarming picture: Intrathecal IgA synthesis combined with blood CSF barrier dysfunction, sometimes with an irritating low cell count, not typical for a bacterial meningitis. So the intrathecal IgA synthesis, common to these cases, allows the characterization of a suspicious round nodule detected by the imaging techniques.

The fast diagnosis of a bacterial meningitis which is based on cell count, total protein and lactate analysis does not need an immunoglobulin analysis. But in case of a brain abscess this basic pattern analysis may be life-saving.

\section{X-linked adrenoleucodystrophy (ALD)}

An intrathecal IgA synthesis was observed in 13/14 young children with a symptomatic cerebral adrenoleucodystrophy $^{32}$ but not in asymptomatic cases or cases of adrenomyeloneuropathy. In three cases of this symptomatic ALD, there was an additional intrathecal IgG or IgM synthesis, the barrier function was slightly increased in 9/14 cases with QAlb $<13.5 \times 10^{-3}$, typical for a chronic course of neurologic diseases. Lactate in CSF was normal (different from neurotuberculosis with IgA synthesis) and the M,R,Z reaction was absent (different from the also demyelinating process in MS). The demyelination is detected by the MRI analysis correlated with the symptomatic disease ${ }^{32}$. The IgA synthesis is secondary to the demyelination in ALD. But the predominant appearance of the IgA isotype is different from the classical demyelinating disease, the MS, with a predominant B cell immigration of the IgG class.

CSF analysis in this example of a genetically determined metabolic disease can contribute to the differential diagnosis but also to the understanding of the pathological processes ${ }^{28}$ for a selective intrathecal IgA synthesis.

\section{Neurosyphilis - absence of intrathecal IgA and neuroimmunological scar}

As shown earlier ${ }^{5}$ the immunoglobulin pattern of a neurosyphilis is characterized by an intrathecal IgG synthesis (of course with OCB) and with a strong intrathecal IgM synthesis in case of parenchymatous and less intense or absent in a vascular pathomechanism of the disease ${ }^{5}$. But in both cases the absence of an intrathecal IgA synthesis is a typical part of the intrathecal immune response.

Neurosyphilis is also a representative example for duration of intrathecal synthesis: Still up to 20 years after sufficient treatment ${ }^{19}$, a slowly decaying treponema-AI can be found increased. This delay of normalization is also seen in cases of neuroborreliosis. A reactivation or reinfection can only be detected by the change of blood parameters like IgM class antibodies or increased cell count in CSF but not by the intrathecal humoral immune response. In this case persisting B-cells in brain have no pathological relevance.

It has to be kept in mind that intrathecal synthesis can be a neuroimmunological scar and should not be misinterpreted as a reason for treatment.

\section{Opportunistic brain diseases : Three class immune reponse}

Due to the improved therapies for HIV patients in the wealthy countries, the opportunistic infections declined. Nevertheless it remains a diagnostic demand to discriminate opportunistic diseases of the brain.

The early HIV encephalopathy with an immunoglobulin pattern in the normal range (Figure 4), but oligoclonal bands in CSF, increased HIV-AI > 1.5, a slightly increased cell count and a normal barrier function is significantly different from an opportunistic toxoplasmosis (Figure 4) with a three class immune response with or without a barrier dysfunction and a significantly increased cell count. Any picture like this with a two- or three-class immune response ${ }^{19}$ is indicative of an opportunistic infection with the demand to search for the causative antigen (toxoplasma, cryptococcus, etc).

The third case with an isolated intrathecal IgM synthesis (Figure 4), together with immune responses like in the first case, is typical for an opportunistic Non-Hodgkin lymphoma. Due to changes in the treatment regime this opportunistic tumor is declined in HIV patients, but may be oberved in other conditions like a iatrogenic immune deficiency.

The corresponding comments in the CSF report could be:

- Intrathecal three-class responses with HIV AI $\geq 1.5$ indicate opportunistic infection (recommendation: analysis of the respective antibodies, or PCR for relevant microorganisms) or Isolated intrathecal IgM synthesis in case of a HIV encephalopathy may be indicative for a Non-Hodgkin lymphoma.

\section{Parasitoses and CSF flow rate}

The diagnosis of paracytoses ${ }^{2,10,11,12,13}$ is either easy or a demanding challenge. The detection of the paracyte in blood may need just a microscope. But the detection of the brain involvement asks for neuroimmaging and CSF analysis. As many of the parasitoses are endemic in (rural) areas with a poor medical infrastructure the diagnosis of a brain involvement becomes a serious problem for the practitioner. The less the economical resources the more important becomes a sophisticated cost-efficient sequence of analytical procedures $^{2,5}$ based on screening methods leading to the more specific analysis.

Additionally, with the worldwide migration dynamics parasitoses are not restricted to the tropical countries and screening methods are necessary to alert the physicians in the northern countries for an unexpected diagnosis to request the subsequent, suitable specific analysis ${ }^{2}$.

A complete CSF data pattern analysis may represents such a screening method, as described for the neurotuberculosis 
with a dominant IgA synthesis (above and Figure 1) or the neurotrypanosomiasis (Figure 2) where the predominant IgM in the intrathecal immunoglobulin pattern is of crucial diagnostic relevance ${ }^{10}$.

But, at time of first diagnostic puncture there may be no information from the immunoglobulin pattern like in the acute eosinic meningoencephalitis in children induced by angiostrongylus cantonensis ${ }^{14}$ which starts with a blood CSF barrier dysfunction without humoral immune response. A three class immune response appears only about 7 days later with the fast normalization of the barrier dysfunction (s. Figure 18.1 in Reiber and Schmutzhard ${ }^{13}$ ). So in these cases the eosinic pleocytosis in blood and CSF is the predominant sign, common with other nematodes ${ }^{13}$.

A particular diagnostic challenge comes from the complicated life cycles of the cestodes and trematodes ${ }^{13}$. As for all helminthes the neuroimmaging is of diagnostic priority. But there is a particular need in these cases to discriminate between locations in brain, spine and extraparenchymal manifestations or involvement of the spinal roots. For these cases CSF analysis can offer crucial information from the changes in CSF flow rate and the different dynamics of molecules from blood, brain and leptomeninges in CSF.

The new understanding of the blood CSF barrier dysfunction as a reduced CSF flow rate ${ }^{17,22}$ has an important potential for sophisticated interpretations.

In neurocysticercosis ${ }^{33}$ the restriction of CSF flow by cysticerci in extraparenchymal locations are well known and discussed as source for hydrocephalus ${ }^{33}$. The insensitive detection of extraparenchymal cysticerci by $\mathrm{CT}$ and $\mathrm{MRI}^{33} \mathrm{em}-$ phasizes quite general the relevance of CSF analysis. The increased albumin quotient (Qalb) ${ }^{4}$ is the indicator for the blockage of CSF flow way in the extraparenchymal, subarachnoidal space and helps to discriminate from parenchymatous neurocysticercosis ${ }^{2,33}$. But, in addition to the sheer analysis of albumin the comparison of blood-derived with brain-derived proteins in lumbar CSF may be a still more specific help.

In the neuroschistosomiasis ${ }^{34}$ the severity of the disease depends on the different localizations, the amount of the eggs and the surrounding inflammatory process. Different from the cysticerci in the subarachnoidal space here the increased Qalb (reduced CSF turnover rate) in lumbar region comes eventually from a blockage of the CSF outflow at the spinal roots (like in radiculitis Guillain Barré). In this case of an outflow blockage the relation of the brain-derived to blood-derived proteins in lumbar CSF are normal ${ }^{16,17}$. This is different from cases of increased Qalb below a spinal blockage (Froin's syndrom, cysticerci, tumor, disc prolaps) with a relatively reduced concentration of brain-derived proteins in lumbar CSF. So these different dynamics of the brain-derived, blood-derived and leptomeningeal molecules $^{16,17}$ in CSF may offer a crucial help to discriminate between the different forms of the spinal cord mansonic neuroschistosomiasis ${ }^{34}$.
These considerations explain why total protein analysis can not replace the separate analysis of single proteins in CSF. The rough correlation between albumin and total protein in $\mathrm{CSF}^{5}$ is not helpful for differential diagnosis in cases with an intense immune response in blood ${ }^{10}$ or brain ${ }^{3}$ or with different contributions of brain-derived proteins in CSF, described above.

\section{Multiple sclerosis and the polyspecific MRZ antibody reaction}

In MS patients but also in patients with an autoimmune disease with involvement of the brain (neurolupus, Sjögren syndrome) the intrathecal synthesis of affinity-maturated IgG class antibodies shows a uge variety of antigen specificities ${ }^{26}$.

All antibodies for which the MS patient had a former systemic infection or immunization ${ }^{26}$ can be found synthesized in brain with frequencies between $10 \%$ and $30 \%$ (see complementary review ${ }^{4}$ and references ${ }^{35,36,37,38,39}$ ). But the frequencies are extraordenary high for measles antibodies (up to 80\%), rubella antibodies ( up to 67\%) and VZV antibodies (up to $63 \%$ ) with a combined frequency for one to three of them, with up to $96 \%$ and for the more specific frequency of the diagnostic relevant combination of two to three increased antibody Index values up to $75 \%$ of the MS cases individually depending on the total amount of intrathecal $\operatorname{IgG}^{36,39}$. In spite of decades of research with changing targets there is no indication of a causative role ${ }^{35}$ of the virus antibodies, the role of intrathecal B cells is regarded to be specificity independent ${ }^{26}$.

Due to its high frequency this so called MRZ antibody reaction is diagnostically relevant.

The analysis is less sensitive than detection of Oligoclonal IgG bands but more specific than oligoclonal IgG or the immune response pattern (Figure 5) for detection of a chronic inflammatory process, most common for MS and less frequent for autoimmune diseases with involvement of the brain. This immune response is either present already in the first monosymptomatic phase of the disease or remains absent as an indication for another disease ${ }^{26,36}$. There is no CSF data supported "conversion" to an MS. This wrong impression comes mainly from variations by insensitive methods.

The MRZ antibody reaction allows an earliest detection of the monosymptomatic disease and a discrimination from an acute demyelinating encephalomyelits $(\mathrm{ADEM})^{36}$.

As another example of a diagnosis-related comment in the CSF report in this case of an MRZ antibody reaction we could read:

- "Positive MRZ reaction: chronic inflammation (autoimmune type). Differential diagnosis: multiple sclerosis or autoimmune disease with involvement of the central nervous system".

The MRZ antibody reaction is superior to the imaging techniques which cannot discriminate different causes of demyelination (s. adrenoleucodystrophy) or other diseases “mimicking” MS 37,3839 . 


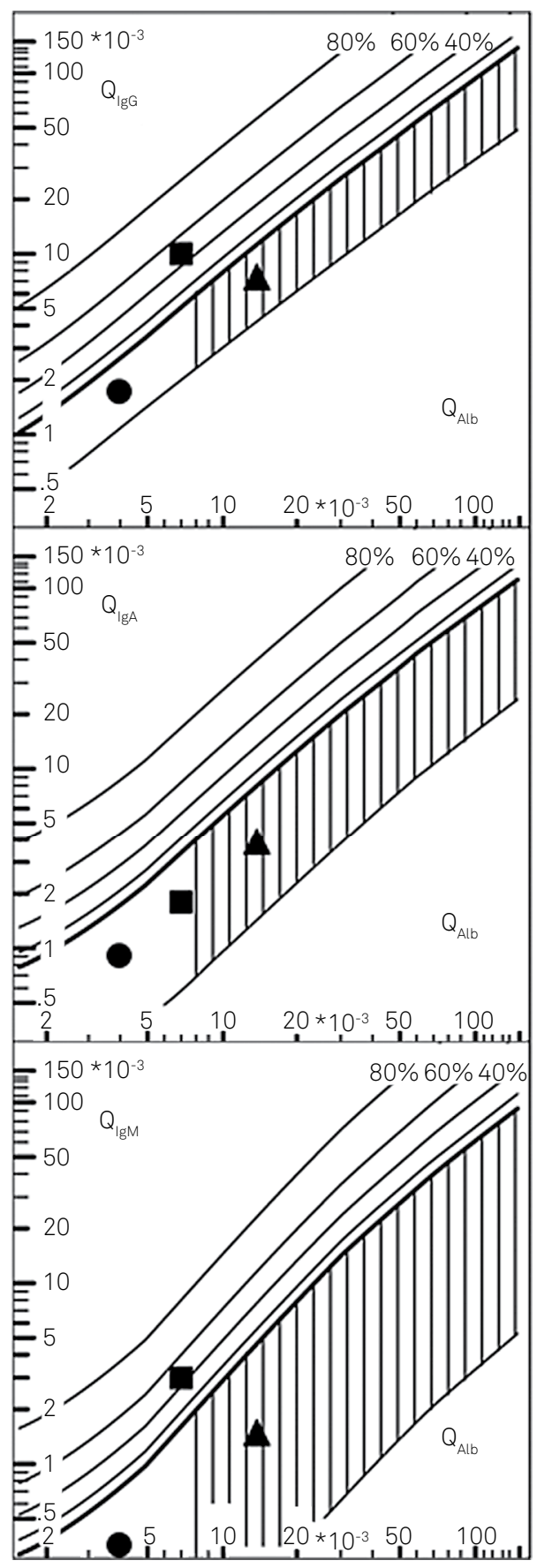

Figure 5. CSF patterns from patients with initial symptoms of a schizophrenic spectrum disorder. Squares: Final diagnosis Multiple sclerosis, Oligoclonal IgG (type 2), Cell count $=5 / \mu \mathrm{L}$ (slightly increased), QAlb $=7 \times 10^{-3}$ is age-related increased (age of patient 30 years), i.e. a blood CSF barrier dysfunction. Circles: Final diagnosis schizophrenic spectrum disorder, QAlb $=14 \times 10^{-3}$ (Blood-CSF barrier dysfunction), oligoclonal IgG neg. (type 1), Cell count $=3 / \mu \mathrm{L}$, neopterin concentration in CSF normal. Triangles: Final diagnosis schizophrenic spectrum disorder, QAlb $=4 \times 10^{-3}$, normal blood CSF barrier function, oligoclonal IgG neg (Type1), Cell count $=3 / \mu \mathrm{L}$, neopterin concentration in CSF increased.

\section{Psychiatric diseases}

Many neurological diseases are accompanied by psychosyndromes. In some cases the neurological disease becomes apparent only by the initial psychiatric symptoms. So multiple sclerosis patients with initial exclusive symptoms of the bipolar spectrum disorder might see first a psychiater and might get a false symptomatic treatment, if CSF is not analysed (Figure 5). This defines the primary target of CSF analysis in psychiatry: the exclusion of CSF abnormalities ${ }^{40}$.

Due to the high frequency of oligoclonal IgG (isoelectric focussing not CSF electrophoresis) in chronic inflammatory diseases this analysis is the basic information a psychiatrist should ask for, to exclude an inflammatory cause of psychiatric symptoms, like in the cases with MS (Figure 5).

But the results of CSF analysis may be more complex as the following analytical results may show:

- In $30 \%$ of the patients with an affective or schizophrenic spectrum disorder the albumin quotient is increased ${ }^{40}$, i.e., decreased CSF flow rate, eventual without any other CSF abnormalities (Figure 5). In the same group, independent from the patients with increased albumin, another $30 \%$ of these patients had an increased concentration of brain-derived neopterin in $\mathrm{CSF}^{40,41}$, without any other signs of humoral or cellular immune response (Figure 5). The carefully investigated absence of any other signs of inflammation or intoxication leaves these observations so far without a diagnostic relevance. The exclusion of medication-caused changes is a crucial precondition for the reliable interpretation of these CSF data in psychiatric patients, most of which have multiple drug treatments.

- In another group of psychiatric patients with an autoimmune encephalitis or systemic tumors with antineuronal antibodies, the inflammatory, immunological cause of their psychiatric symptoms is easier detectable by analysis of the corresponding antibodies in blood and eventually in $\mathrm{CSF}^{42}$.

- In a subgroup of the affective and schizophrenic spectrum disorders minor unspecific changes like activated CSF monocytes or increased CSF cytokines may give plausibilities for an inflammatory context ${ }^{43}$. But small molecules, like cytokines, which are metabolized on the way between brain and lumbar CSF, lumbar CSF data can not be reliably interpreted regarding the situation in the brain. CSF Neopterin is one of the few exceptions ${ }^{41}$.

- Since 1991, after the first Gulf war, new groups of psychiatric diseases were recognized as part of a "Post war stress syndrome" and "Combat-related post-traumatic stress disorder (PTSD)", which may be examples of psychiatric disorders with an immunological background ${ }^{44}$. Veterans began to exhibit fatigue, fevers, rashes, joint pain, intestinal problems, memory loss, mood swings and even cancers, a cluster of symptoms and conditions now referred to as "Gulf war syndrome" (English term) or "Dessert storm syndrome" (US term). In fact about 800.000 troups have been vaccinated with more then 8 vaccines in a short time of about two weeks. About $20 \%$ of the soldiers developed in the following 3-4 weeks the very variable spectrum of symptoms now accepted in the US as a chronic organic disease, different from 
the English patients which are diagnosed to have a "Post war stress syndrome" and eventually some patients were treated in psychiatry with electroconvulsive therapy (The Guardian). There is a uge field of immunological research as we learn from post immunization problems in the normal population with similar symptoms, that the symptoms in the Golf war syndrome could be due to postimmunization problems ${ }^{44}$. But with the cases of the post-lyme-syndrome, discussed with the neuroborreliosis above, we have to consider these diseases in the wider context of the selforganized immunological network reactions ${ }^{26,44,45,46}$.

These examples show a dilemma of psychiatric diagnosis and therapies if the analytical approaches do not include CSF and corresponding blood analysis. This is a request for an update of the Diagnostic and Statistical Manual of Mental Disorders (DSM of the American Psychiatric Association) or international proposals for diagnostics in Psychiatry.

As well as in neurology, for psychiatric diagnosis a complete spectrum of CSF analysis is advised. Independent from a diagnostic relevance, CSF analysis may help to characterize the elementary fields of psychiatry for real mental diseases, discriminated from psychiatric symptoms accompaning immunological reactions with a necessarily different therapeutic approach.

\section{Chronic diseases}

The largest fraction of diseases in the Northern countries are the diseases with a chronic course. The understanding of chronic diseases, their development and their pathologies as well as the development of causal therapies is the greatest challenge for modern medicine. The cause of an acute bacterial meningitis may easily be detected and with the antibiotic treatment the steady worsening of pathological processes stopped. In such a case the body itself would not be able to limit the fast bacterial expansion with invasion of 10- to 100- thousands of cells into CSF and brain and a fast death. This is different in a chronic pathologic process where the causative antigen may either be locally restricted as in the eye in a Fuchs' heterochromic cyclitis ${ }^{47}$ or may be not persisting at all as in multiple sclerosis ${ }^{26}$. In these cases the pathological process is less fatal, the body may have found a spacial or timely selflimiting regulation process. A model for such an immune reaction ${ }^{48}$ is described for variation of the viral load eather leading to death, to immunity or at low viral amounts to a chronic process with persisting antigen and intermediate antibody concentrations, not in the state of immunity ${ }^{48}$, but representing a stable regulatory state ${ }^{45}$.

From a CSF diagnostic point of view we find such limited changes in CSF of chronic inflammatory processes: a restricted increase of the cell count $(<20 / \mu \mathrm{L})$ and only slightly, if at all, increased QAlb $\left(<15 \times 10^{-3}\right)$. I.e., a cell count of $100 / \mu \mathrm{L}$ or a QAlb value of $50 \times 10^{-3}$ are not compatible with the diagnosis of an MS or an autoimmune disease with involvement of the brain (e.g. a neurolupus). Another characteristic of chronic diseases in CSF is the intrathecal IgG class response which is stable in the individual patient over long times, but individually at different levels of intensity ${ }^{36}$.

In general we observe in many diseases like high blood pressure, chronic heart diseases with heartbeat variability, osteoporosis with changed parathormon regulation, etc., stable pathological states which show in their regulation processes an increase of order or correspondingly a decrease of complexity $^{45}$. This is best seen in the electroencephalogram of an epileptic seizure where time series of alpha waves change from a chaotic to a rhythmic time course.

This is the field of selforganizing complex systems ${ }^{45}$ which are not accessible by linear cause and consequence thinking. Part of this is the successless search for the gene-related pathologies, now continued in the epigenetics ${ }^{45,46}$ which must fail as well due to their linear approach.

A progress in research for chronic pathological processes in Neurology as well as in mental diseases of psychiatry will only be reached if the diseases are understood as stable emergent properties of a selforganizing complex system. In these cases one would not expect a loss, a new appearance or any change of molecular parameters except their change in concentration fluctuations in time as an expression of a change in complexity of regulation ${ }^{45,46}$.

\section{Tumors and brain metastases - the diagnostic CSF space}

The analysis of carcino-embryonic-antigen (CEA) in CSF and serum and its evaluation in quotient diagrams taught us two important aspects of CSF analysis:

- The diagrams with hyperbolic discrimination lines are applicable for all serum proteins, not only immunoglobulins ${ }^{19}$.

- The place of the pathological process in brain is the most important factor for the diagnostic sensitivity of CSF analysis.

A diagnosis of a meningeal carcinosis or intraparenchymal metastasis of a CEA synthesizing tumor (mamma, colon etc.) is detectable by an intrathecal synthesis of the carcino embryonic antigen. The extremely low mean concentration of CEA in normal CSF $(2,7 \mathrm{ng} / \mathrm{L})^{49}$ may have been a handycap for more frequent applications of this powerful method. With the fact that CEA concentrations in blood (and subsequently in CSF) are hundred- to thousand-fold increased in case of a systemic CEA synthesizing tumor, the concentrations in CSF became measurable and the discrimination between a systemic restricted tumor and a meningeal carcinosis became easier to be detected ${ }^{19}$. Figure 6 shows an intraparenchymal metastasis with an intermediate barrier dysfunction and relatively small intrathecal CEA fraction $\left(\mathrm{Q}_{\mathrm{CEA}}=46 \times 10^{-3}\right.$; CEA IF $\left.=64 \%\right)$ and a meningeal carcinosis with severe barrier dysfunction (restriction of CSF flow) and extremely high intrathecal CEA $\left(\mathrm{Q}_{\mathrm{CEA}}=1387 \times 10^{-3}\right.$; CEA IF $\left.=97 \%\right)$. The third case with nor$\mathrm{mal}_{\mathrm{CEA}}$ is either a colon-restricted tumor without a meningeal carcinosis and a barrier dysfunction from another cause or an intraparechymal metastasis far from diagnostic CSF space. 
Due to the same effective molecular size as IgA (QIgA = QCEA), CEA can be evaluated with the IgA diagrams ${ }^{19}$. The high intrathecal CEA fraction in CSF (Figure 6) with up to $99 \%$ is obtained due to relatively small ${ }^{16}$ blood-derived CEA concentration. But as shown ${ }^{49}$ the intrathecal CEA synthesis is detected only if the intraparenchymal metastasis is near the CSF space. With the early work on CEA as a tumor marker by Felgenhauer and Jacobi ${ }^{49}$ for diagnosis of a meningeal carcinosis or intraparenchymal metastasis the idea of a diagnostic relevant CSF space was developed. A metastasis in the frontal lobe would not be recognized in CSF due to the long diffusion way. This is the reason why the CSF analysis of MS has such a high sensitivity: in most of the patients the circumventricular space is involved.

In 5-7\% of brain tumors the presence of oligoclonal IgG bands in CSF indicate a secondary local inflammation without diagnostic relevance.

A possible comment in the CSF report could be:

- intrathecal synthesis of carcinoembryonic antigen (CEA) with $\mathrm{Q}_{\mathrm{CEA}}>\mathrm{Q}_{\mathrm{Lim}}$ (IgA) or $\mathrm{Q}_{\mathrm{CEA}}>\mathrm{Q}_{\mathrm{IgA}}$ indicates a tumor metastasis in the brain.

Only the pathological processes near the subarachnoid space can be recognized in CSF analysis: the diagnostic CSF space in brain.

\section{Variability of disease-related immunoglobulin patterns}

The described "typical" disease-related patterns of the immune response (IgG, IgA, IgM), shown in the examples in the Figures 1-6, refer to the first, "diagnostic" lumbar puncture. Their specificities are founded by a large number of observations over decades of years. The frequency by which these typical patterns occur, i.e., their diagnostic sensitivities may be between $30 \%$ to $100 \%$ due to different variabilities. The time of puncture in the course of the disease depends on the cause of the disease. A patient with a bacterial meningitis appears in the hospital already at the first day for a lumbar puncture, with a viral encephalitis evtl after a week and with a neurotuberculosis as late as three weeks after start of the disease $^{3}$. The variability may also depend on the localisation of the disease in brain. E.g., the detection of intrathecal CEA is missed in case of a frontotemporal localization of the metastasis ( s.above). This means that the presence of a certain pattern is an indication for the disease, but the absence of CSF abnormalities mean not that the disease (or a brain metastasis) does not exist.

Other variations may come from different pathomechanisms in a disease as described above for the neurosyphilis.

In the HSV encephalitis the intrathecal immune response becomes detectable only after one to two weeks (as oligoclonal IgG and $\operatorname{IgG}_{\mathrm{IF}}>0$ in a one class immune response) but can later, depending on the course of the disease, develop temporarily an intrathecal IgA and IgM synthesis (Figure 19.4b in Wildemann et al. ${ }^{3}$ ).

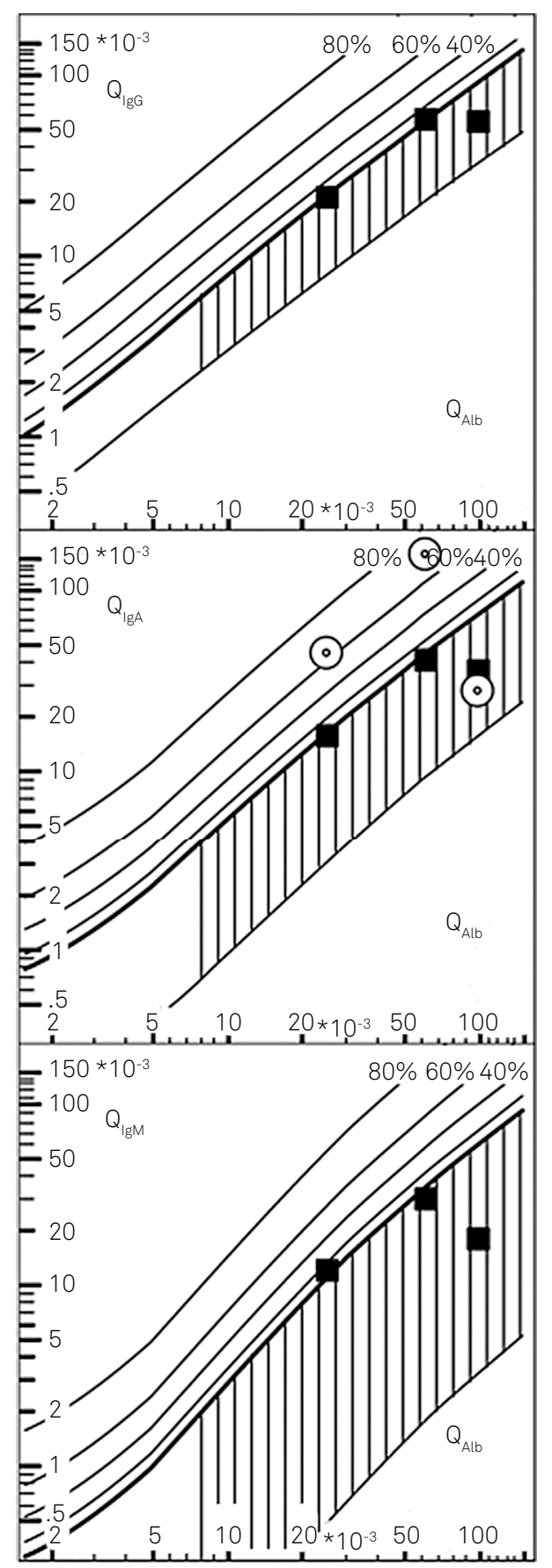

Figure 6. CSF analysis of Carcino-embryonic antigen (CEA): Differential diagnosis of a meningeal carcinosis or intraparenchymal metastasis for patients with a systemic CEA synthesizing tumor. The CSF/serum concentration quotients (open circles with a center point) are evaluated in the IgA diagram. From left to right: Case 1, an intraparenchymal metastasis with an intermediate barrier dysfunction and relatively small intrathecal CEA quotient $\left(Q_{C E A}=46 \times 10^{-3} ; C A_{E E}=64 \%\right)$, $\mathrm{CC}=32 / \mu \mathrm{L}$ increased, lactate normal, serum-CEA $=4,4 \mathrm{\mu g} / \mathrm{L}$. Case 2, a meningeal carcinosis with severe barrier dysfunction and extremely high intrathecal CEA quotient $\left(Q_{\mathrm{CEA}}=1387 \times 10^{-3}\right.$; $\mathrm{CEA}_{\mathrm{F}}=97 \%$ ), serum CEA $=6,2 \mu \mathrm{g} / \mathrm{L} . \mathrm{CC}=13 / \mu \mathrm{L}$ increased. Lactate $7,0 \mathrm{mmol} / \mathrm{l}$ erhöht. Case 3, with normal $Q_{C E A}</=Q_{\text {IoA }}$ lactate $=3,6 \mathrm{mmol} / \mathrm{l}$ is increased, $\mathrm{CC}=10 / \mu \mathrm{L}$ is increased, CEA in serum with $31,3 \mu \mathrm{g} / \mathrm{L}$ is very high. Alternative interpretations: a colon-restricted tumor without a meningeal carcinosis and with a barrier dysfunction from another cause - or - an intraparechymal metastasis far from diagnostic CSF space. 
In multiple sclerosis the obligatory intrathecal $\operatorname{IgG}$ occationally is accompanied by an IgM $(<55 \%)$ and rarely by an IgA $(<17 \%)$ synthesis. The comparison with the patterns in the eye and CSF of the individual patient shows that in spite of similar statistical frequencies in eye and brain, in the individual patient the IgM and IgA isotype patterns are arbitrarily variable ${ }^{26}$. A particular information comes also for the antibody patterns (MRZ antibody reaction) with arbitrarily varying in the individual patient in spite of statistically similar frequencies in both body fluids ${ }^{26,47}$.

These examples indicate the limits of a software supported, knowledge based interpretation in cases of missing typical patterns which leave the final interpretation to the experienced neurologists knowledge and intuition to associate variants to the correct diagnosis.

\section{References}

1. Livramento JA, Machado LR. The history of cerebrospinal fluid analysis in Brazil. Arq Neuropsiquiatr. 2013;71(9B):649-52. doi:10.1590/0004-282X20130143

2. Machado LR, Livramento JA, Vianna LS. Cerebrospinal fluid analysis in infectious diseases of the nervous system: when to ask, what to ask, what to expect. Arq Neuropsiquiatr. 2013;71(9B):693-8. doi:10.1590/0004-282X20130153

3. Wildemann B, Oschmann P, Reiber H, editors. Laboratory diagnosis in neurology. Stuttgart: Thieme; 2010.

4. Reiber H. Knowledge-base for interpretation of cerebrospinal fluid data patterns. Essentials in Neurology and Psychiatry. Arq Neuropsiquiatr. 2016;74. In press.

5. Reiber H, Peter JB. Cerebrospinal fluid analysis: disease-related data patterns and evaluation programs. J Neurol Sci. 2001;184(2):101-22. doi:10.1016/S0022-510X(00)00501-3

6. Reiber H, Otto M, Trendelenburg C, Wormek A. Reporting cerebrospinal fluid data - knowledge base and interpretation software. Clin Chem Lab Med. 2001;39(4):324-32. doi:10.1515/CCLM.2001.051

7. Siemens. Protis sytem. 2016 [cited 2016-03-20]. Available from: http://www.healthcare.siemens.com/diagnostics-it/decisionsupport/protis-system

8. Reiber H, Albaum W. Statistical evaluation of intrathecal protein synthesis in CSF/Serum quotient diagrams [free software: CSF Statistics Tool at www.albaum.it]. Acta Neuropsychiatr. 2008;2 Suppl1:48-9.

9. Regeniter A, Kuhle J, Mehling M, Möller H, Wurster U, Freidank H et al. A modern approach to CSF analysis: pathophysiology, clinical application, proof of concept and laboratory reporting. Clin Neurol Neurosurg. 2009;111(4):313-8. doi:10.1016/j.clineuro.2008.12.004

10. Lejon V, Reiber H, Legros D, Djé N, Magnus E, Wouters I et al. Intrathecal immune response pattern for improved diagnosis of central nervous system involvement in trypanosomiasis. J Infect Diseases. 2003;187(9):1475-83. doi:10.1086/374645

11. Puccioni-Sohler M, (org). Diagnóstico de neuroinfecção: com abordagem dos exames do líquido cefalo-raquidiano e neuroimagem. Rio de Janeiro: Rubio; 2008.

12. Costa Neto, JB, editor. Liquido cefalorraquiano. Campo Grande: Life; 2013.

13. Reiber H, Schmutzhard E. Parasitoses and tropical diseases. In: Wildemann B, Oschmann P, Reiber H, editors. Laboratory diagnosis in neurology. Stuttgart: Thieme; 2010. p. 226-32.

14. Kluge $\mathrm{H}$, Wieczorek E, Linke E, Zimmermann K, Isenmann S, Witte OW. Atlas of CSF cytology: with an interactive training course (CD-ROM). Stuttgart: Thieme; 2007.

15. Dorta AJ, Reiber H. Intrathecal synthesis of immunoglobulins in eosinophilic meningoencephalitis due to Angiostrongylus cantonensis. Clin Diagn Lab Immunol 1998;5(4):452-5.

16. Reiber H. Dynamics of brain-derived proteins in cerebrospinal fluid. Clin Chim Acta. 2001;310(2):173-86. doi:10.1016/S0009-8981(01)00573-3
17. Reiber H. Proteins in cerebrospinal fluid and blood: barriers, CSF flow rate and source-related dynamics. Restor Neurol Neurosci. 2003;21(3-4):79-96.

18. Reiber H. Principles of analytical methods. In: Wildemann B, Oschmann P, Reiber H, editors. Laboratory diagnosis in neurology. Stuttgart: Thieme; 2010. p. 17-29.

19. Reiber H. CSF analysis report. In: Wildemann B, Oschmann P, Reiber $H$, editors. Laboratory diagnosis in neurology. Stuttgart: Thieme; 2010. p. 235-48.

20. Reiber H. The discrimination between different blood-CSF barrier dysfunctions and inflammatory reactions of the CNS by a recent evaluation graph for the protein profile of CSF.J Neurol. 1980;224(2):89-99. doi:10.1007/BF00313347

21. Reiber H, Felgenhauer K. Protein transfer at the blood-CSF barrier and the quantitation of the humoral immune response within the central nervous system. Clin Chim Acta. 1987;163(3):319-28. doi:10.1016/0009-8981(87)90250-6

22. Reiber H. Flow rate of cerebrospinal fluid (CSF): a concept common to normal blood-CSF barrier function and to dysfunction in neurological diseases. J Neurol Sci. 1994;122(2):189-203. doi:10.1016/0022-510X(94)90298-4

23. Dorta-Contreras AJ, Reiber H, Magraner-Tarrau ME, Weissbrick B, Interián-Morales MT, Noris-García E et al. Valor neuroinmunoepidemiológico del Reibergrama en la primera epidemia de meningoencefalitis por echovirus 16 en Cuba. Rev Neurol. 2002;35(6):517-20.

24. Reiber H, Rostasy K. Response to the letter of Villar et al. 'Quantitative and qualitative IgM analysis in CSF'. Mult Scler. 2012;18:252-3. doi:10.1177/1352458511418144

25. Faber R, Trendelenburg C. Interpretation of CSF quantities with the knowledge-based system Pro.M.D.: cerebrospinal fluid diagnostics. J Lab Med. 1997;21(5):257-82. doi:10.1515/labm.1997.21.5.275

26. Reiber H, Kruse-Sauter H, Quentin C. Antibody patterns vary arbitrarily between cerebrospinal fluid and aqueous humor of the individual multiple sclerosis patient: specificity-independent pathological B cell function. J Neuroimmunol. 2015;278:247-54. doi:10.1016/j.jneuroim.2014.11.013

27. Sindic CJ, Delacroix DL, Vaerman JP, Laterre EC, Masson PL. Study of IgA in the cerebrospinal fluid of neurological patients with special reference to size, subclass and local production. J Neuroimmunol. 1984;7(2-3):65-75. doi:10.1016/S0165-5728(84)80007-7

28. Mantis NJ, Rol N, Corthésy B. Secretory IgA's complex roles in immunity and mucosal homeostasis in the gut. Mucosal Immunol. 2011;4(6):603-11. doi:10.1038/mi.2011.41

29. Reiber H, Ressel CB, Spreer A. Diagnosis of neuroborreliosis-Improved knowledge base for qualified antibody analysis and cerebrospinal fluid data pattern related interpretations. Neurol Psychiatry Brain Res. 2013;19(4):159-69. doi:10.1016/j.npbr.2013.10.004 
30. Lejon V, Robays J, N'Siesi FX, Mumba D, Hoogstoel A, Bisser S et al. Treatment failure related to intrathecal immunoglobulin $\mathrm{M}$ (IgM) synthesis, cerebrospinal fluid IgM, and interleukin-10 in patients with hemolymphatic-stage sleeping sickness. Clin Vaccine Immunol. 2007;14(6):732-7. doi:10.1128/CVI.00103-07

31. Araújo A, Reinhard K, Ferreira LF, Pucu E, Chieffi PP. Paleoparasitology: the origin of human parasites. Arq Neuropsiquiatr. 2013;71(9B):722-6. doi:10.1590/0004-282X20130159

32. Korenke GC, Reiber H, Hunneman DH, Hanefeld F. Intrathecal IgA synthesis in X-linked cerebral adrenoleukodystrophy. J Child Neurol. 1997;12(5):314-20. doi:10.1177/088307389701200505

33. Takayanagui OM. Neurocysticercosis. Arq Neuropsiquiatr. 2013;71(9B):710-3. doi:10.1590/0004-282X20130156

34. Carvalho OAM. Mansonic neuroschistosomiasis. Arq Neuropsiquiatr. 2013;71(9B):714-6. doi:10.1590/0004-282X20130157

35. Olival GS, Lima BM, Sumita LM, Serafim V, Fink MC, Nali LH et al.Multiple sclerosis and herpes virus interaction. Arq Neuropsiquiatr. 2013;71(9B):727-30. doi:10.1590/0004-282X20130160

36. Reiber H, Teut M, Pohl D, Rostasy KM, Hanefeld F. Paediatric and adult multiple sclerosis: age related differences and time course of the neuroimmunological response in cerebrospinal fluid. Multiple Scler. 2009;15(12):1466-80. doi:10.1177/1352458509348418

37. Rocha AJ, Littig IA, Nunes RH, Tilbery CP. Central nervous system infectious diseases mimicking multiple sclerosis, recognizing distinguishable features using MRI. Arq Neuropsiquiatr. 2013;71(9B):738-46. doi:10.1590/0004-282X20130162

38. Puccioni-Sohler M, Kitze B, Felgenhauer K, Graef IT, Lange P, Novis $S$ et al. The value of CSF analysis for the differential diagnosis of HTLV-1 associated myelopathy and multiple sclerosis. Arq Neuropsychiatr. 1995;53(4):760-5. doi:10.1590/S0004-282X1995000500008

39. Reiber H, Ungefehr St, Jacobi Chr. The intrathecal, polyspecific and oligoclonal immune response in multiple sclerosis. Mult Scler. 1998;4(3):111-7. doi:10.1177/135245859800400304
40. Bechter K, Reiber H, Herzog S, Fuchs D, Tumani H, Maxeiner HG. Cerebrospinal fluid analysis in affective and schizophrenic spectrum disorders. Identification of subgroups with immune responses and blood-CSF barrier dysfunction. J Psychiatr Res. 2010;44(5):321-30. doi:10.1016/j.jpsychires.2009.08.008

41. Kuehne LK, Reiber H, Bechter K, Hagberg L, Fuchs D. Cerebrospinal fluid neopterin is brain-derived and not associated with blood-CSF barrier dysfunction in non-inflammatory affective and schizophrenic spectrum disorders. J Psychiatr Res. 2013;47(10):1417-22. doi:10.1016/j.jpsychires.2013.05.027

42. Wildemann B, Wurster U. Autoantibodies and Antineural antibodies. In: Wildemann B, Oschmann P, Reiber H, editors. Laboratory diagnosis in neurology. Stuttgart: Thieme; 2010. p. 86-98.

43. Bechter K. Updating the mild encephalitis hypothesis of schizophrenia. Prog Neuropsychopharmacol Biol Psychiatry. 2013;42(5):71-91. doi:10.1016/j.pnpbp.2012.06.019

44. Reiber H, Davey B. Desert Storm syndrome and immunization. Arch Internal Med. 1996;156(2):217. doi:10.1001/archinte.156.2.217

45. Reiber H. Komplexität und Selbstorganisation stabiler biologischer Gestalt in Epigenese und Evolution - Von der genozentrischen zur phänozentrischen Biologie. In: Kaasch M, Kaasch J, Hrsg. Biologie und Gesellschaft. Verhandlungen zur Geschichte und Theorie der Biologie. Verlag für Wissenschaft und Bildung, Berlin, 2012, Bd. 17: 37-80.

46. Reiber H. Epigenesis and epigenetics: understanding chronic diseases as a selforganizing stable phenotype. Neurol Psych Brain Res. 2012;18(2):79-81. doi:10.1016/j.npbr.2012.02.001

47. Quentin CD, Reiber H. Fuchs heterochromic cyclitis: rubella virus antibodies and genome in aqueous humor. Am J Ophthalmol. 2004;138(1):46-54. doi:10.1016/j.ajo.2004.02.055

48. Mayer $\mathrm{H}$, Zaenker KS, van der Heiden U. A basic mathematical model of the immune response. Chaos 1995; 5:155-161.

49. Jacobi C, Reiber H, Felgenhauer K. The clinical relevance of the locally produced carcinoembryonic antigen in cerebrospinal fluid. J Neurol. 1986;233(6):358-61. doi:10.1007/BF00313922 